\title{
An overview of cancer/testis antigens expression in classical Hodgkin's lymphoma (CHL) identifies MAGE-A family and MAGE-C1 as the most frequently expressed antigens in a set of Brazilian $\mathrm{CHL}$ patients
}

Riguel J Inaoka ${ }^{1 \dagger}$, Achim A Jungbluth ${ }^{2 \dagger}$, Otávio CG Baiocchi ${ }^{1}$, Mariane CG Assis ${ }^{1}$, Nicole C Hanson ${ }^{2}$, Denise Frosina ${ }^{2}$, Jodie Tassello², Adriana B Bortoluzzo ${ }^{3}$, Antonio C Alves ${ }^{4}$ and Gisele WB Colleoni ${ }^{* *}$

\begin{abstract}
Background: Cancer/testis antigens are considered potential targets for immunotherapy due to their tumorassociated expression pattern. Although recent studies have demonstrated high expression of CT45 in classical Hodgkin's lymphomas (CHL), less is known about the expression pattern of other families of CTAs in CHL. We aim to evaluate the expression of MAGE-A family, MAGE-C1/CT7, MAGE-C2/CT10, NY-ESO1 and GAGE family in CHL and to correlate their expression with clinical and prognostic factors in $\mathrm{CHL}$.

Methods: Tissue microarray was generated from $38 \mathrm{cHL}$ archival cases from Pathology Department of Universidade Federal de Sao Paulo. Immunohistochemistry (IHC) was done using the following panel of antibodies: MAGE-A family (MA454, M3H67, 57B and 6C1), GAGE (\#26), NY-ESO-1 (E978), MAGE-C1/CT7 (CT7-33) and MAGE-C2/CT10 (CT10\#5).

Results: We found CTA expression in $21.1 \%$ of our $\mathrm{CHL}$ series. Among the tested CTAs, only MAGE-A family $7 / 38$ (18.4\%) and MAGE-C1/CT7 5/38 (13.2\%) were positive in our CHL samples. We found higher CTA positivity in advanced stage (28.6\%) compared to early stage (11.8\%) disease, but this difference was not statistically significant. Analysis of other clinicopathological subgroups of $\mathrm{CHL}$ including histological subtypes, EBV status and response to treatment also did not demonstrate statistical significant differences in CTA expression.

Conclusion: We found CTA expression in $21.1 \%$ of $\mathrm{CHL}$ samples using our panel. Our preliminary findings suggest that from all CTAs included in this study, MAGE-A family and MAGE-C1/CT7 are the most interesting ones to be explored in further studies.
\end{abstract}

Keywords: Hodgkin?'?s Lymphoma, cancer/testis antigens

\section{Background}

Classical Hodgkin lymphoma (cHL) is characterized by the presence of rare neoplastic Hodgkin-Reed-Sternberg (HRS) cells embedded in an inflammatory background of nonmalignant cells $[1,2]$. The mechanisms of how

\footnotetext{
* Correspondence: gcolleoni@unifesp.br

† Contributed equally

${ }^{1}$ Departamento de Oncologia Clinica e Experimental, Universidade Federal de Sao Paulo. Rua Botucatu, 740, Vila Clementino, Sao Paulo, SP 04023-900, Brazil

Full list of author information is available at the end of the article
}

HRS cells survive in this inflammatory milieu remain controversial and the identification of specific antigens restricted to the HRS cells is crucial for the development of new treatment strategies, augmenting host antitumor immunological response.

Cancer/testis antigens (CTAs) are considered potential candidates for antigen-specific cancer immunotherapy due to their particular characteristics of high immunogenicity with no or highly restricted expression in normal tissues (testis and placenta) [3]. There are more than 100 CTA genes reported in the literature to date

\section{C) BiolMed Central}


[4] but biological function of most CTAs remains poorly understood. Recent studies have provided some evidence that CTAs may have antiapoptotic properties rather than regulating cell proliferation or adhesion in cancer [5-12] and it could explain the persistence of minimal residual disease in some malignancies, even in $\mathrm{cHL}$, where the potential of cure is very high. The frequency of CTA expression is highly variable among different tumor types. Melanoma, ovarian cancer, and lung cancer are considered tumors with high frequency of CTA expression, while hematopoietic malignancies, renal, colon and pancreatic cancers, are considered tumors with low frequency of CTA expression [3]. Some exceptions to this observation among hematopoietic malignancies are the high expression of CT7/ MAGE-C1 in multiple myeloma $[13,14]$, and CT45 in classical Hodgkin lymphoma (cHL) $[15,16]$. Studies correlating CTA expression with clinicopathological features in different tumor types have demonstrated the association of CTA positivity with higher tumor grade, advanced stage or metastatic disease and worse clinical outcome [13,17-25].

Considering that the available information about CTA expression in $\mathrm{CHL}$ is scarce and heterogeneous regarding methods and samples, we investigated the immunohistochemical expression against a broad panel of CTAs in $\mathrm{CHL}$ tissue samples to evaluate their potential as prognostic markers and candidates for immunotherapeutic approach in $\mathrm{cHL}$ patients.

\section{Methods}

We retrospectively reviewed all cases of cHL diagnosed between 2004 and 2008 at the University Hospital São Paulo. Medical records from 38 adult patients (> 18 years) with cHL were reviewed and information on sex, age at diagnosis, Ann Arbor clinical stage, laboratory results, treatment used and response were retrieved. The response to primary treatment was classified according to the International Workshop criteria [26]. Patients treated with radiotherapy alone as first-line therapy and with positive HIV serology were excluded from this study. For this study, only cHL patients with tumors whose histology could be confirmed by hemopathologist re-review and paraffin blocks with enough material for tissue microarray (TMA) construction could be retrieved were studied. Sufficient data was obtained from 38 patients. All patients received ABVD (doxorubicin, bleomycin, vinblastine and dacarbazine) chemotherapy protocol and had locally extensive or advanced stage disease at diagnosis. Locally extensive disease was defined by clinical stages I-II-A/B (Ann Arbor Staging System) with massive mediastinal adenopathy (mass $>$ $1 / 3$ maximum intrathoracic diameter on standing postero-anterior chest $\mathrm{x}$-rays), and advanced disease defined as stages III-IV. Determination of EBV-association in tumor biopsies was done by immunohistochemistry for latent membrane protein 1 (LMP1) following previously established procedures [27]. Samples from a known EBV-related cHL served as a positive control in each run.

This research was approved by the Ethical Review Committee of our Institution according to the Declaration of Helsinki (0998/07), and all patients provided written informed consent.

Formalin-fixed paraffin embedded tissues of $38 \mathrm{cHL}$ were obtained from the archives of the Department of Pathology, Hospital São Paulo, UNIFESP, Brazil. All HL cases were classified according to WHO classification for hematologic malignancies [28] as cHL. 25 (65.8\%) cases were classified as nodular sclerosis subtype, 9 (23.7\%) as mixed cellularity, $2(5.3 \%)$ as lymphocyte predominant and 2 (5.3\%) were unclassified. Table 1 summarizes the clinical data of these patients. Slides from all cases were reviewed and representative blocks were chosen for tissue microarray.

Two core-needle biopsies (1.0 $\mathrm{mm}$ diameter) from tumor representative areas of each HL case were obtained and then re-embedded in an array master block using techniques originally developed by Kononen et al. [29] and then modified by Hedvat et al. [30] and Beecher Instruments (Sun Prairie, WI, USA) arraying device.

The mAbs used for immunohistochemistry are listed in Table 2 [22,31-38]. The evaluation of MAGE-A family expression was done using a "MAGE-A cocktail"

Table 1 Clinical data of Hodgkin's lymphoma patients (n = 38).

\begin{tabular}{lll}
\hline Clinical data & $\mathbf{n}$ & $\%$ \\
\hline $\begin{array}{l}\text { Median age: 28.5 (16-57) } \\
\text { Gender }\end{array}$ & & \\
$\quad$ Male & 18 & 47.4 \\
$\quad$ Female & 20 & 52.6 \\
HL Subtype & & \\
$\quad$ Nodular sclerosis & 25 & 65.8 \\
$\quad$ Mixed cellularity & 9 & 23.7 \\
$\quad$ Lymphocyte predominant & 2 & 5.3 \\
$\quad$ Unclassified & 2 & 5.3 \\
Ann Arbor staging & & \\
$\quad$ Early (I or II) & 17 & 44.7 \\
$\quad$ Advanced (III or IV) & 21 & 55.3 \\
EBV status & & \\
$\quad$ Negative & 21 & 55.3 \\
$\quad$ Positive & 17 & 44.7 \\
Response & & \\
$\quad$ Complete response & 30 & 78.9 \\
$\quad$ Relapsed/refractory & 8 & 21.1 \\
\hline
\end{tabular}


Table 2 Monoclonal antibodies used in immunohistochemical analyses.

\begin{tabular}{lllll}
\hline $\begin{array}{l}\text { Monoclonal } \\
\text { antibody }\end{array}$ & $\begin{array}{l}\text { Mainly recognized } \\
\text { Antigen(s) }\end{array}$ & Source & Cellular staining & References \\
\hline MA454* & MAGE-A1 & LICR & Cytoplasmic & {$[22,31-34]$} \\
M3H67* & MAGE-A3 & LICR & Nuclear \& cytoplasmic & {$[22,33,34]$} \\
57B * & MAGE-A4 & Dr Spagnoli, Basel, Switzerland & Nuclear \& cytoplasmic & {$[22,33,34]$} \\
6C1* & MAGE-A 1, 2, 3, 4, 6, 10 and 12 & LICR & Nuclear \& cytoplasmic & {$[35]$} \\
CT7-33 & CT7/MAGE-C1 & LICR & Nuclear \& cytoplasmic & {$[22,33,34]$} \\
CT10\#5 & CT10/MAGE-C2 & LICR & Nuclear & {$[35-37]$} \\
\#26 & GAGE & BD Bioscience & Nuclear \& cytoplasmic & {$[35,36]$} \\
E978 & NY-ESO-1 & LICR & Cytoplasmic & {$[36,38]$} \\
\hline
\end{tabular}

*MAbs included in "MAGE-A cocktail" used to search MAGE-A family expression in HL TMA.

containing the following antibodies: MA454, M3H67, 57B and $6 \mathrm{C} 1$, that allowed an overview of MAGE-A family (MAGE-A1, MAGE-A2, MAGE-A3, MAGE-A4, MAGEA6 MAGE-A10 and MAGE-A12) expression in HL.

Testis with preserved spermatogenesis was used as positive controls and reactive lymph nodes and tonsils samples were used as negative controls for all antibodies.

Associations between the variables were tested by the Pearson Chi-Square Test $\left(\mathrm{X}^{2}\right)$. Mann-Whitney test was used to perform mean comparisons. A p value lower than 0.05 was considered as statistically significant.

\section{Results}

The majority of patients presented advanced disease and B symptoms at diagnosis. We found a strong correlation between anti-LMP1 identification on HRS cells and response to ABVD regimen, with all $21 \mathrm{EBV}$-negative patients achieving complete response (CR) and only 9/ 17 (52.9\%) of EBV-positive patients achieving CR ( $\mathrm{p}<$ 0.001 ). None of other clinical subgroups presented statistical significant difference in treatment response, as demonstrated on Table 3.

Due to the low overall CTA expression in CHL TMA, positivity was not graduated, and the samples were analyzed as positive (any degree of positivity) or negative. Figure 1 demonstrates three nodular sclerosis cHL samples stained for CT7. Sample (A) shows diffuse positivity, sample (B) is focally positive and sample $(C)$ is a negative case.

Eight (21.1\%) of $38 \mathrm{cHL}$ cases expressed at least one CTA, being 6/25 nodular sclerosis and $2 / 9$ mixed cellularity. Among the 8 positive cases, $6 / 20$ were female and $2 / 18$ male. Despite the difference found in CTA expression between early (11.8\%) and advanced stage (28.6\%) disease, this difference was not statistically significant ( $p$ $=0.195$ ). None of the other clinical subgroups of $\mathrm{cHL}$ according to histological subtypes, EBV status and response to treatment also presented statistically significant difference in CTA expression, as demonstrated on
Table 4. Among the tested CTAs, only MAGE-A family 7/38 (18.4\%) and MAGE-C1/CT7 5/38 (13.2\%) were positive in our cHL samples. CT10/MAGE-C2, GAGE and NY-ESO-1 were negative in all samples. Four of these samples were positive for both CTAs.

\section{Discussion and conclusions}

In our study, the majority of cases had B symptoms (68.4\%) and advanced disease (65.7\%) at diagnosis, as

Table 3 Hodgkin's lymphoma treatment response analysis.

\begin{tabular}{|c|c|c|c|c|c|}
\hline Clinical data & $N$ & $\begin{array}{l}\text { Complete } \\
\text { response } \\
(\%)\end{array}$ & $\mathrm{N}$ & $\begin{array}{l}\text { Refractory/ } \\
\text { relapsed } \\
\text { (\%) }\end{array}$ & $\begin{array}{l}p \\
\text { value }\end{array}$ \\
\hline \multicolumn{6}{|l|}{ Gender } \\
\hline Male & 13 & 72.2 & 5 & 27.8 & 0.286 \\
\hline Female & 17 & 85.0 & 3 & 15.0 & \\
\hline \multicolumn{6}{|l|}{ HL Subtype } \\
\hline Nodular sclerosis & 21 & 84.0 & 4 & 16.0 & 0.220 \\
\hline Mixed cellularity & 5 & 55.6 & 4 & 44.4 & \\
\hline $\begin{array}{l}\text { Lymphocyte } \\
\text { predominant }\end{array}$ & 2 & 100.0 & 0 & 0 & \\
\hline Unclassified & 2 & 100.0 & 0 & 0 & \\
\hline \multicolumn{6}{|l|}{ Ann Arbor staging } \\
\hline Early (I or II) & 15 & 88.2 & 2 & 11.8 & 0.195 \\
\hline Advanced (III or IV) & 15 & 71.4 & 6 & 28.6 & \\
\hline \multicolumn{6}{|l|}{ EBV status } \\
\hline Negative & 21 & 100.0 & 0 & 0 & $\begin{array}{l}< \\
0.001\end{array}$ \\
\hline Positive & 9 & 52.9 & 8 & 47.1 & \\
\hline \multicolumn{6}{|l|}{ CTA positivity } \\
\hline $0 \mathrm{CT}$ & 24 & 80.0 & 6 & 20.0 & 0.954 \\
\hline$>$ or $=1$ & 6 & 75.0 & 2 & 25.0 & \\
\hline \multicolumn{6}{|l|}{ MAGE-A } \\
\hline negative & 24 & 77.4 & 7 & 22.6 & 0.538 \\
\hline positive & 6 & 85.7 & 1 & 14.3 & \\
\hline \multicolumn{6}{|l|}{ CT7 } \\
\hline negative & 27 & 81.8 & 6 & 18.2 & 0.279 \\
\hline positive & 3 & 60 & 2 & 40 & \\
\hline
\end{tabular}




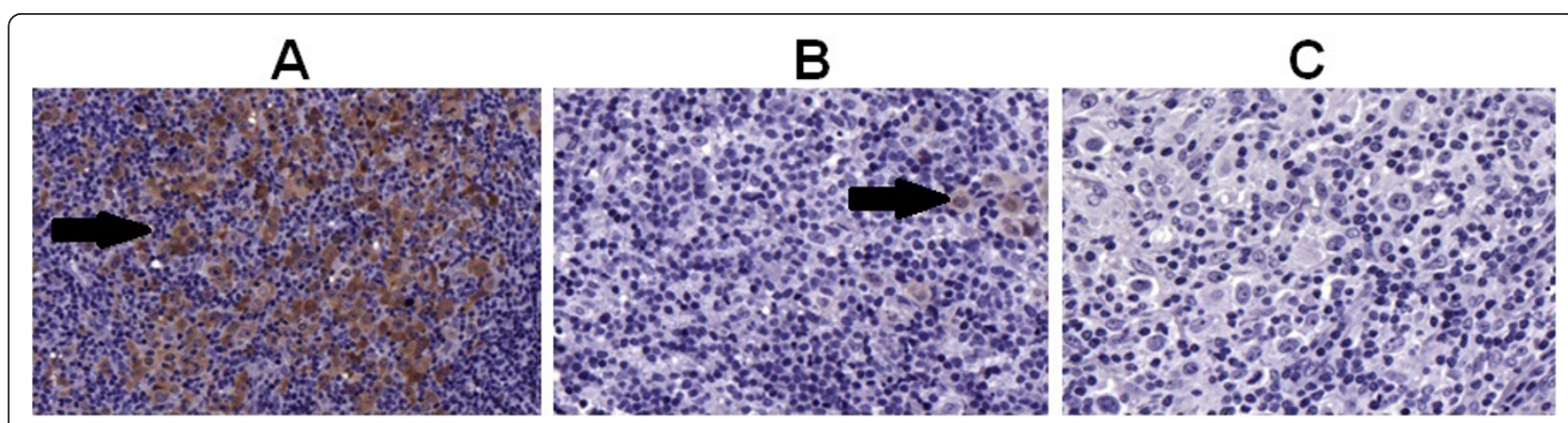

Figure 1 Immunohistochemical staining of three different nodular sclerosis cHL samples using an anti-CT7 antibody (CT7-33). (A) Diffuse positivity. (B) Focal positivity. (C) Negative staining for CT7-33; $\times 400$.

seen in other developing countries. The positivity for EBV was $44.7 \%$ in our cohort of cHL. According to literature, the incidence of EBV-related cHL is highly variable among different populations and higher EBV positivity has seen in underdevelopment countries compared to developed ones. In previous studies, Oliveira et al. and Vassallo et al. found EBV positivity in $52.5 \%$ and $64.1 \%$ of Brazilian cHL patients respectively $[39,40]$. The prognostic significance of EBV expression is controversial, but the correlation of EBV positivity and poorer outcome has been described in some studies [41]. The difference of treatment failure rate between EBV positive (47.1\%) and EBV negative patients (0\%) was statistically significant $(\mathrm{p}<0.001)$ in our cohort.

Using our panel, we found expression of CTAs in $21.1 \%$ of cHL patients. MAGE-A family was positive in $18.4 \%$ and MAGE-C1/CT7 in 13.2\% of samples. Despite the availability of few studies evaluating the expression of CTAs in cHL to date, our findings are in agreement with most of studies that evaluated the expression of same

Table 4 Hodgkin's lymphoma CTA expression analysis.

\begin{tabular}{llllll}
\hline Clinical data & N & $\begin{array}{l}\mathbf{0} \text { CTA } \\
\text { (\%) }\end{array}$ & $\begin{array}{l}\mathbf{N} \\
\text { (\%) }\end{array}$ & $\begin{array}{l}\text { or = 1 CTA } \\
\text { value }\end{array}$ \\
\hline $\begin{array}{l}\text { HL Subtype } \\
\quad \text { Nodular sclerosis }\end{array}$ & 19 & 76.0 & 6 & 24.0 & 0.752 \\
$\quad \begin{array}{l}\text { Mixed cellularity } \\
\quad \text { Lymphocyte predominant }\end{array}$ & 2 & 100.0 & 0 & 0 & \\
$\quad$ Unclassified & 2 & 100.0 & 0 & 0 & \\
$\begin{array}{l}\text { Ann Arbor staging } \\
\quad \text { Early (I or II) }\end{array}$ & 15 & 88.2 & 2 & 11.8 & 0.195 \\
$\quad$ Advanced (III or IV) & 15 & 71.4 & 6 & 28.6 & \\
EBV status & & & & & \\
$\quad \begin{array}{l}\text { Negative } \\
\quad \text { Positive }\end{array}$ & 17 & 81.0 & 4 & 19.0 & 0.522 \\
Treatment Response & 13 & 76.5 & 4 & 23.5 & \\
$\quad$ Complete response & 24 & 80.0 & 6 & 20.0 & 0.954 \\
$\quad$ Non Complete response & 6 & 75.0 & 2 & 25.0 & \\
\hline
\end{tabular}

CTAs in cHL using RT-PCR or immunohistochemical analysis. Expression of MAGE-A family in cHL was evaluated by Chambost et al. [42] and it was positive in $28 \%$ of cHL samples using RT-PCR and in $21 \% \mathrm{cHL}$ tissue sections using immunohistochemistry with an antiMAGE-A4 antibody. Recently, Chen et al. [15] described the expression of CT45 in cHL and other B-cell lymphomas. They found expression of CT 45 in $58 \%$ of cHL by immunohistochemistry. A previous study published by Heidebrecht et al. [16] also described the expression of CT45 in 55\% of pediatric and adolescent cHL using immunohistochemistry, reinforcing CT45 as one of the most promising CTA to be explored in cancer vaccine trials for cHL to date. Unfortunately, CT45 could not be included in our immunohistochemistry panel because specific antibodies were not commercially available, neither at Ludwig Institute for Cancer Research - NY, our collaborating center at the time of this study. Another CTA family whose expression pattern was studied in CHL was SSX. Colleoni et al. [43] found positivity of SSX family in $15.6 \%$ of $32 \mathrm{cHL}$ samples. In summary, except for CT45, the available studies suggest an overall positivity for other CTA families tested in cHL of about $10 \%$ to $30 \%$. We found a tendency to a higher CTA expression among advanced stage disease compared to early stage disease in our cHL samples as described in literature [13,17-25], but the difference did not reach statistical significance.

Therefore, our results emphasize the importance of studying CTAs expression in a Brazilian set of patients. We acknowledge the fact that our small sample size may have influenced these results, and larger studies are warranted. However, our results point toward a relationship between CTA expression and disease severity.

Further studies investigating CTA expression on HRS cells and how they can elicit humoral and cytotoxic response will contribute not only to our understanding on the pathogenesis of cHL but also to the development 
of new CTA-directed immunotherapy, particularly for advanced stage cases and for patients who did not achieve a complete response after initial therapy.

\author{
Acknowledgements \\ This work was partially supported by grants from CAPES (RJI) and CNPq \\ (GWBC).
}

\section{Author details}

${ }^{1}$ Departamento de Oncologia Clinica e Experimental, Universidade Federal de Sao Paulo. Rua Botucatu, 740, Vila Clementino, Sao Paulo, SP 04023-900, Brazil. ${ }^{2}$ Ludwig Institute for Cancer Research New York Branch, Memorial Sloan-Kettering Cancer Center, 1275 York Avenue, Box 32, New York, NY 10021-6007, USA. ${ }^{3}$ Instituto de Ensino e Pesquisa, Insper. Rua Quata, 300, Vila Olimpia, Sao Paulo, SP 04546-042, Brazil. ${ }^{4}$ Departamento de Anatomia Patologica, Universidade Federal de Sao Paulo. Rua Botucatu, 740, Vila Clementino, Sao Paulo, SP 04023-900, Brazil.

\section{Authors' contributions}

This manuscript is a product of a PhD research project (RJ) conducted under the supervision of GWBC. AAJ, NH, DF and JT (Ludwig Institute for Cancer Research - NY) participated in the decision of (TAs to be included in our study, provided the anti-CTA antibodies and carried out the immunohistochemistry. OCGB and MCGA participated in acquisition, analysis and interpretation of $\mathrm{CHL}$ clinical data. ABB performed the statistical analysis. ACA reviewed all CHL tumor sample slides. RJ participated in all steps described above and drafted the manuscript. GWBC have been involved in conception and design of this study, analysis, interpretation of data and final approval of the version to be published. All authors read and approved the final manuscript.

\section{Competing interests}

The authors declare that they have no competing interests.

Received: 27 May 2011 Accepted: 28 September 2011

Published: 28 September 2011

\section{References}

1. Skinnider BF, Mak TW: The role of cytokines in classical Hodgkin lymphoma. Blood 2002, 99:4283-4297.

2. Poppema S: Immunobiology and pathophysiology of Hodgkin lymphomas. Hematology Am Soc Hematol Educ Program 2005, 231-238.

3. Caballero OL, Chen YT: Cancer/testis (CT) antigens: potential targets for immunotherapy. Cancer Sci 2009, 100(11):2014-21.

4. Almeida LG, Sakabe NJ, de Oliveira AR, Silva MC, Mundstein AS, Cohen T, Chen YT, Chua R, Gurung S, Gnjatic S, Jungbluth AA, Caballero OL, Bairoch A, Kiesler E, White SL, Simpson AJ, Old L, Camargo AA, Vasconcelos AT: CTdatabase: a knowledge-base of high-throughput and curated data on cancer-testis antigens. Nucleic Acids Res 2009, 37:D816-9.

5. Atanackovic D, Hildebrandt $Y$, Jadczak A, Cao Y, Luetkens T, Meyer $S$, Kobold S, Bartels K, Pabst C, Lajmi N, Gordic M, Stahl T, Zander AR, Bokemeyer C, Kröger N: Cancer-testis antigens MAGE-C1/CT7 and MAGEA3 promote the survival of multiple myeloma cells. Haematologica 2010, 95(5):785-93.

6. Zhu X, Asa SL, Ezzat S: Fibroblast growth factor 2 and estrogen control the balance of histone 3 modifications targeting MAGE-A3 in pituitary neoplasia. Clin Cancer Res 2008, 14:1984-96.

7. Yang B, O'Herrin SM, Wu J, Reagan-Shaw S, Ma Y, Bhat KM, Gravekamp C, Setaluri V, Peters N, Hoffmann FM, Peng H, Ivanov AV, Simpson AJ, Longley BJ: MAGE-A, mMage-b, and MAGE-C proteins form complexes with KAP1 and suppress p53-dependent apoptosis in MAGE-positive cell lines. Cancer Res 2007, 67:9954-62.

8. Peikert T, Specks U, Farver C, Erzurum SC, Comhair SA: Melanoma antigen A4 is expressed in non-small cell lung cancers and promotes apoptosis. Cancer Res 2006, 66:4693-700.

9. Monte M, Simonatto M, Peche LY, Bublik DR, Gobessi S, Pierotti MA, Rodolfo M, Schneider C: MAGE-A tumor antigens target p53 transactivation function through histone deacetylase recruitment and confer resistance to chemotherapeutic agents. Proc Natl Acad Sci USA 2006, 103:11160-5.

10. Bai $\mathrm{S}, \mathrm{He}$ B, Wilson EM: Melanoma antigen gene protein MAGE-11 regulates androgen receptor function by modulating the interdomain interaction. Mol Cell Biol 2005, 25:1238-57.

11. Nagao T, Higashitsuji H, Nonoguchi K, Sakurai T, Dawson S, Mayer RJ, Itoh K, Fujita J: MAGE-A4 interacts with the liver oncoprotein gankyrin and suppresses its tumorigenic activity. J Biol Chem 2003, 278:10668-74.

12. Cilensek ZM, Yehiely F, Kular RK, Deiss LP: A member of the GAGE family of tumor antigens is an anti-apoptotic gene that confers resistance to Fas/CD95/APO-1, Interferon-gamma, taxol and gamma-irradiation. Cancer Biol Ther 2002, 1:380-7.

13. Andrade VC, Vettore AL, Felix RS, Almeida MS, Carvalho F, Oliveira JS, Chauffaille ML, Andriolo A, Caballero OL, Zago MA, Colleoni GW: Prognostic impact of cancer/testis antigen expression in advanced stage multiple myeloma patients. Cancer Immun 2008, 8:2.

14. Jungbluth AA, Ely S, DiLiberto M, Niesvizky R, Williamson B, Frosina D, Chen YT, Bhardwaj N, Chen-Kiang S, Old LJ, Cho HJ: The cancer-testis antigens CT7 (MAGE-C1) and MAGE-A3/6 are commonly expressed in multiple myeloma and correlate with plasma-cell proliferation. Blood 2005, 106:167-74.

15. Chen YT, Chadburn A, Lee P, Hsu M, Ritter E, Chiu A, Gnjatic S, Pfreundschuh M, Knowles DM, Old L: Expression of cancer testis antigen CT45 in classical Hodgkin lymphoma and other B-cell lymphomas. Proc Natl Acad Sci USA 2010, 107(7):3093-8.

16. Heidebrecht HJ, Claviez A, Kruse ML, Pollmann M, Buck F, Harder S, Tiemann M, Dörffel W, Parwaresch R: Characterization and expression of CT45 in Hodgkin's lymphoma. Clin Cancer Res 2006, 12:4804-11.

17. Velazquez EF, Jungbluth $A A$, Yancovitz M, Gnjatic S, Adams S, O'Neill D, Zavilevich K, Albukh T, Christos P, Mazumdar M, Pavlick A, Polsky D, Shapiro R, Berman R, Spira J, Busam K, Osman I, Bhardwaj N: Expression of the cancer/testis antigen NY-ESO-1 in primary and metastatic malignant melanoma (MM) - correlation with prognostic factors. Cancer Immun 2007, 7:11.

18. Goydos JS, Patel M, Shih W: NY-ESO-1 and CTp11 expression may correlate with stage of progression in melanoma. J Surg Res 2001, 98:76-80.

19. Suyama T, Shiraishi T, Zeng Y, Yu W, Parekh N, Vessella RL, Luo J, Getzenberg RH, Kulkarni P: Expression of cancer/testis antigens in prostate cancer is associated with disease progression. Prostate 2010, 70(16):1778-87.

20. Riener MO, Wild PJ, Soll C, Knuth A, Jin B, Jungbluth A, Hellerbrand C, Clavien PA, Moch H, Jochum W: Frequent expression of the novel cancer testis antigen MAGE-C2/CT-10 in hepatocellular carcinoma. Int J Cancer 2009, 124:352-7.

21. Atanackovic D, Luetkens T, Hildebrandt Y, Arfsten J, Bartels K, Horn C, Stahl T, Cao Y, Zander AR, Bokemeyer C, Kröger N: Longitudinal analysis and prognostic effect of cancer-testis antigen expression in multiple myeloma. Clin Cancer Res 2009, 15:1343-52.

22. Perez D, Herrmann T, Jungbluth AA, Samartzis P, Spagnoli G, Demartines N, Clavien PA, Marino S, Seifert B, Jaeger D: Cancer testis antigen expression in gastrointestinal stromal tumors: new markers for early recurrence. Int $J$ Cancer 2008, 123(7):1551-5.

23. Bellati F, Napoletano C, Tarquini E, Palaia I, Landi R, Manci N, Spagnoli G, Rughetti A, Panici PB, Nuti M: Cancer testis antigen expression in primary and recurrent vulvar cancer: association with prognostic factors. Eur J Cancer 2007, 43(17):2621-7.

24. Kim J, Reber HA, Hines OJ, Kazanjian KK, Tran A, Ye X, Amersi FF, Martinez SR, Dry SM, Bilchik AJ, Hoon DS: The clinical significance of MAGEA3 expression in pancreatic cancer. Int J Cancer 2006, 118:2269-75.

25. Yakirevich E, Sabo E, Lavie O, Mazareb S, Spagnoli GC, Resnick MB: Expression of the MAGE-A4 and NY-ESO-1 cancer-testis antigens in serous ovarian neoplasms. Clin Cancer Res 2003, 9:6453-60.

26. Brepoels L, Stroobants S, De Wever W, Spaepen K, Vandenberghe P, Thomas J, Uyttebroeck A, Mortelmans L, De Wolf-Peeters C, Verhoef G: Hodgkin lymphoma: Response assessment by revised International Workshop Criteria. Leuk Lymphoma 2007, 48:1539-1547.

27. Campos AH, Aldred VL, Ribeiro KC, Vassallo J, Soares FA: Role of immunoexpression of nitric oxide synthases by Hodgkin and ReedSternberg cells on apoptosis deregulation and on clinical outcome of classical Hodgkin lymphoma. Mol Cell Biochem 2009, 321:95-102. 
28. Swerdlow SH, Campo E, Harris NL, Jaffe ES, Pileri SA, Stein H, Thiele J, Vardiman JW: World Health Organization Classification of Tumours. Pathology and Genetics of Tumours of Haematopoietic and Lymphoid Tissues. IARC Press, Lyon 2008.

29. Kononen J, Bubendorf L, Kallioniemi A, Bärlund M, Schraml P, Leighton S, Torhorst J, Mihatsch MJ, Sauter G, Kallioniemi OP: Tissue microarrays for high-throughput molecular profiling of tumor specimens. Nat Med 1998, 4:844-847.

30. Hedvat CV, Hegde A, Chaganti RS, Chen B, Qin J, Filippa DA, Nimer SD, Teruya-Feldstein J: Application of tissue microarray technology to the study of non-Hodgkin's and Hodgkin's lymphoma. Hum Pathol 2002, 33:968-974.

31. Chen $Y T$, Stockert $E$, Chen $Y$, Garin-Chesa P, Rettig WJ, van der Bruggen $P$, Boon T, Old L: Identification of the MAGE-1 gene product by monoclonal and polyclonal antibodies. Proc Natl Acad Sci USA 1994, 91(3):1004-8.

32. Jungbluth AA, Stockert E, Chen $Y T$, Kolb D, Iversen $K$, Coplan $K$, Williamson B, Altorki N, Busam KJ, Old LJ: Monoclonal antibody MA454 reveals a heterogeneous expression pattern of MAGE-1 antigen in formalin-fixed paraffin embedded lung tumours. $\mathrm{Br} J$ Cancer 2000, 83(4):493-7.

33. Dhodapkar MV, Osman K, Teruya-Feldstein J, Filippa D, Hedvat CV, Iversen K, Kolb D, Geller MD, Hassoun H, Kewalramani T, Comenzo RL, Coplan K, Chen YT, Jungbluth AA: Expression of cancer/testis (CT) antigens MAGEA1, MAGE-A3, MAGE-A4, CT-7, and NY-ESO-1 in malignant gammopathies is heterogeneous and correlates with site, stage and risk status of disease. Cancer Immun 2003, 3:9.

34. Nelson PT, Zhang PJ, Spagnoli GC, Tomaszewski JE, Pasha TL, Frosina D, Caballero OL, Simpson AJ, Old LJ, Jungbluth AA: Cancer/testis (CT) antigens are expressed in fetal ovary. Cancer Immun 2007, 7:1.

35. Sharma $P$, Shen $Y$, Wen $S$, Bajorin DF, Reuter VE, Old $L$, Jungbluth $A A$ : Cancer-testis antigens: expression and correlation with survival in human urothelial carcinoma. Clin Cancer Res 2006, 12(18):5442-7.

36. Oba-Shinjo SM, Caballero OL, Jungbluth AA, Rosemberg S, Old LJ Simpson AJ, Marie SK: Cancer-testis (CT) antigen expression in medulloblastoma. Cancer Immun 2008, 8:7.

37. Zhuang R, Zhu Y, Fang L, Liu XS, Tian Y, Chen LH, Ouyang WM, Xu XG, Jian $J$, Güre AO, Fortunato $S$, Ritter $G$, Old $L$, Simpson AJ, Chen $Y T$, Jin B, Jungbluth AA: Generation of monoclonal antibodies to cancer/testis (CT) antigen CT10/MAGE-C2. Cancer Immun 2006, 6:7.

38. Vaughan HA, Svobodova S, Macgregor D, Sturrock S, Jungbluth AA, Browning J, Davis ID, Parente P, Chen YT, Stockert E, St Clair F, Old L, Cebon J: Immunohistochemical and molecular analysis of human melanomas for expression of the human cancer-testis antigens NY-ESO1 and LAGE-1. Clin Cancer Res 2004, 10(24):8396-404.

39. Souza EM, Baiocchi OC, Zanichelli MA, Alves AC, Assis MG, Eiras DP, Dobo C, Oliveira JS: Impact of Epstein-Barr virus in the clinical evolution of patients with classical Hodgkin's lymphoma in Brazil. Hematol Oncol 2010, 28(3):137-41.

40. Vassallo J, Metze K, Traina F, de Souza CA, Lorand-Metze I: Expression of Epstein-Barr virus in classical Hodgkin's lymphomas in Brazilian adult patients. Haematologica 2001, 86(11):1227-8.

41. Diepstra A, van Imhoff GW, Schaapveld M, Karim-Kos H, van den Berg A, Vellenga E, Poppema S: Latent Epstein-Barr virus infection of tumor cells in classical Hodgkin's lymphoma predicts adverse outcome in older adult patients. J Clin Oncol 2009, 27(23):3815-21.

42. Chambost H, Van Baren N, Brasseur F, Godelaine D, Xerri L, Landi SJ, Theate I, Plumas J, Spagnoli GC, Michel G, Coulie PG, Olive D: Expression of gene MAGE-A4 in Reed-Sternberg cells. Blood 2000, 95(11):3530-3.

43. Colleoni GW, Capodieci P, Tickoo S, Cossman J, Filippa DA, Ladanyi M: Expression of SSX genes in the neoplastic cells of Hodgkin's lymphoma. Hum Pathol 2002, 33(5):496-502.

\section{Pre-publication history}

The pre-publication history for this paper can be accessed here: http://www.biomedcentral.com/1471-2407/11/416/prepub

doi:10.1186/1471-2407-11-416

Cite this article as: Inaoka et al:: An overview of cancer/testis antigens expression in classical Hodgkin's lymphoma (CHL) identifies MAGE-A family and MAGE-C1 as the most frequently expressed antigens in a set of Brazilian CHL patients. BMC Cancer 2011 11:416.

\section{Submit your next manuscript to BioMed Central and take full advantage of:}

- Convenient online submission

- Thorough peer review

- No space constraints or color figure charges

- Immediate publication on acceptance

- Inclusion in PubMed, CAS, Scopus and Google Scholar

- Research which is freely available for redistribution

Submit your manuscript at www.biomedcentral.com/submit
Biomed Central 